\title{
Gestational Trophoblastic Neoplasm TNM Finding v8
}

National Cancer Institute

\section{Source}

National Cancer Institute. Gestational Trophoblastic Neoplasm TNM Finding v8. NCI

Thesaurus. Code C140015.

A finding about one or more characteristics of a gestational trophoblastic neoplasm, following the rules of the TNM AJCC v8 classification system. This classification applies to the following placental neoplasms: invasive hydatidiform mole, choriocarcinoma, placental site trophoblastic tumor, and epithelioid trophoblastic tumor. Complete and partial hydatidiform tumors are not included in this classification. (from AJCC 8th Ed.) 